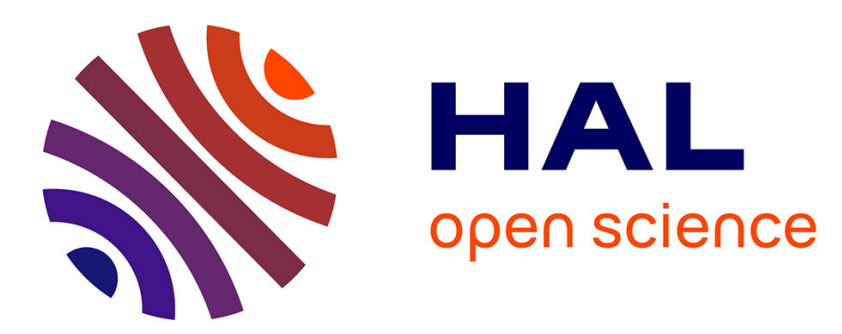

\title{
Calibration of a productivity model for the microalgae Dunaliella salina accounting for light and temperature
}

Quentin Béchet, Philippe Moussion, Olivier A. Bernard

\section{To cite this version:}

Quentin Béchet, Philippe Moussion, Olivier A. Bernard. Calibration of a productivity model for the microalgae Dunaliella salina accounting for light and temperature. Algal Research - Biomass, Biofuels and Bioproducts, 2017, 21, pp.156 - 160. 10.1016/j.algal.2016.11.001 . hal-01410980

\author{
HAL Id: hal-01410980 \\ https://hal.inria.fr/hal-01410980
}

Submitted on 27 Jan 2017

HAL is a multi-disciplinary open access archive for the deposit and dissemination of scientific research documents, whether they are published or not. The documents may come from teaching and research institutions in France or abroad, or from public or private research centers.
L'archive ouverte pluridisciplinaire HAL, est destinée au dépôt et à la diffusion de documents scientifiques de niveau recherche, publiés ou non, émanant des établissements d'enseignement et de recherche français ou étrangers, des laboratoires publics ou privés.

\section{(c)(1)}

Distributed under a Creative Commons Attribution| 4.0 International License 


\section{Calibration of a productivity model for the microalgae}

\section{Dunaliella salina accounting for light and temperature}

3

4 Quentin Béchet ${ }^{\mathrm{a}, \mathrm{b}^{*}}$, Philippe Moussion ${ }^{\mathrm{a}, \mathrm{b}}$, Olivier Bernard $^{\mathrm{a}, \mathrm{b}}$

5

6 a Université Côte d'Azur, Inria, BIOCORE, BP 9306902 Sophia Antipolis Cedex, France

7 b Sorbonne Universités, UPMC Université Paris 06, CNRS, UMR 7093, LOV, Observatoire

8 océanologique, F-06230, Villefranche/mer, France

9

$10 *$ Corresponding author

11 Telephone: +33492387174

12 Fax: + 33492387858

13 Email: quentin.bechet@inria.fr 
14 Abstract

15

16 This study aimed to calibrate a productivity model for the algal species Dunaliella salina

17 accounting for the impacts of light intensity and temperature. The calibration was performed

18 by using a dedicated experimental set-up measuring short-term oxygen production rates at

19 different light intensities. The rate of photosynthesis was shown to follow a typical Monod

20 function of light intensity. The slope of Photosynthesis-light curves at low light intensity was

21 also shown to be independent on temperature and the evolution of model parameters with

22 temperature obeyed relationships consistent with previous observations in the literature.

23 Finally, the rate of respiration was shown to follow an Arrhenius function of temperature.

24 This good level of agreement with prior observations in the literature indirectly validates the

25 experimental technique used for model calibration. The resulting model should therefore yield 26 accurate productivity predictions in outdoor cultivation systems.

27

28 Keywords: Algae; D. salina; growth kinetics; productivity model; photosynthesis; respiration 
1. Introduction

30 With the objective to accurately assess the economical and environmental feasibility of fullscale algal cultivation for biofuel production, a large number of studies developed mathematical models predicting algal productivity in outdoor cultivation systems [1-3]. These models can be used to improve process design or develop optimization strategies maximizing algal productivity. For instance, Slegers et al. [4] used a mathematical model predicting growth rates of Phaeodactylum tricornutum and Thalassiosira pseudonana to optimize the design of closed photobioreactors. Similarly, Béchet et al.[5] proposed an optimization strategy based on the dynamic control of pond depth and hydraulic retention time to increase productivity while reducing water demand, using a productivity model for Chlorella vulgaris. Alternatively, adapting the algal species to climatic conditions could potentially boost yearly algal productivity, similarly to crop rotation used in traditional agriculture. For example, algal species having low optimal temperatures could be cultivated in colder climates or simply during winter while heat-resistant algal species could be grown in summer when pond temperature reaches higher levels. With the objective to assess the benefits of these 'algal culture rotation' strategies, it is necessary to calibrate algal productivity models for a large number of species. However, while many studies in the literature developed productivity models, these models have been calibrated on a limited number of algal species. In particular, the impact of temperature was often neglected in past studies, which limits models application to outdoor systems where temperature significantly varies $[1]$.

51 Within this context, our research group has been developing mathematical models to predict algal productivity in various outdoor cultivation systems from meteorological hourly data, system design and operation. This modeling framework combined models predicting system 
temperature with a biological model predicting algal productivity as a function of light and temperature. So far, the biological model has only been calibrated for a single algal species, Chlorella vulgaris (see Béchet et al. [6]). The objective of this study was therefore to calibrate a productivity model for another algal species, Dunaliella salina, this species being the third most cultivated microalgae [7]. Chlorella vulgaris and Dunaliella salina are both

Chlorophyceae and share the same tolerance to high temperatures. The methodology followed in this study was therefore similar to the calibration technique followed by Béchet et al. [6], and also because the model for $C$. vulgaris accurately predicted productivities in indoor (accuracy of +/- 15\% over 163 days; Béchet et al. [6]) and outdoor (accuracy of +/- 8.4\% over 148 days, Béchet et al. [8]) reactors.

\section{Materials and methods}

2.1. Algae cultivation conditions and biomass characterization

The Chlorophyceae Dunaliella salina (CCAP 19/18) was cultivated in a cylindrical photobioreactor (diameter: $0.19 \mathrm{~m}$; height: $0.41 \mathrm{~m}$; culture volume: $10 \mathrm{~L}$; gas phase volume: 1.6 L). The reactor was illuminated by two metal halide lamps (Osram Powerstar HQI-TS, 150W NDL, Neutralweiss de Luxe) providing a light intensity of $1440 \mu \mathrm{mol} / \mathrm{m}^{2}$-s (measured when the reactor was filled with water with a QSL-2100 PAR scalar irradiance sensor, Biospherical Instruments). Temperature was maintained at $30^{\circ} \mathrm{C}$ by re-circulating temperature-controlled water in a jacket around the reactor. The reactor was inoculated with a culture of $D$. salina (inoculum volume of approximately $500 \mathrm{~mL}$ ) grown in axenic conditions (light intensity: $300 \mu \mathrm{mol} / \mathrm{m}^{2}$-s, light-dark cycle: $12: 12$, temperature: $27^{\circ} \mathrm{C}$ ) and was then operated as a fed-batch system: 9L of solution was replaced every week with fresh $\mathrm{f} / 2$ medium [9] enriched in phosphorus and nitrogen to ensure that algal growth was not limited by nutrients (Total $\mathrm{N}$ and $\mathrm{P}$ concentrations in enriched medium: $0.22 \mathrm{~g} \mathrm{~N}^{-N_{3}}{ }^{-} / \mathrm{L} ; 0.020 \mathrm{~g} \mathrm{P}-$ 
$\left.\mathrm{PO}_{3}{ }^{-} / \mathrm{L}\right)$. Air enriched in $\mathrm{CO}_{2}\left(2 \% \mathrm{CO}_{2}\right)$ was continuously bubbled in the photobioreactor to ensure that $\mathrm{CO}_{2}$ supply did not limit algal growth and also to control $\mathrm{pH}$ between 7 and 7.5. Algae used for model calibration were extracted from the photobioreactor 2-3 days after medium change during the light-limited growth phase. The biomass concentration in the solution used during model calibration was measured by dry weight [10]. Glass-fiber filters (GF/C, Whatman, diameter: $25 \mathrm{~mm}$, No 1822-025) were first dried for several days at $60^{\circ} \mathrm{C}$ before being weighed. A known volume of the algal solution was then filtered; filters were then rinsed with Ammonium formate (30 g/L) to remove salt. Filters were then dried for 24 hours at $60^{\circ} \mathrm{C}$ before being weighed again. Dry weight concentration was measured in duplicates.

\subsection{Productivity model description}

Algal productivity $\left(P_{n e t}\right.$, in $\left.\mathrm{kg} \mathrm{O}_{2} / \mathrm{s}\right)$ was expressed as the difference between the gross rate of photosynthesis $\left(P\right.$, in $\left.\mathrm{kg} \mathrm{O}_{2} / \mathrm{s}\right)$ and the rate of endogenous respiration $\left(E R\right.$, in $\left.\mathrm{kg} \mathrm{O}_{2} / \mathrm{s}\right)[6]$ :

$P_{n e t}=P-E R$

The gross rate of photosynthesis was expressed as a function of light intensity and temperature by using a 'type-II model' as recommended by Béchet et al. [1]. This type of models is based on the assumption that the local rate of photosynthesis of single algal cells can be expressed as a direct function of the local light intensity cells are exposed to. Béchet et al. [6] used different formulas to express local rates of photosynthesis as a function of local light intensity and showed that the three formulas most commonly used in the literature all satisfyingly fit experimental data. The authors finally selected the Monod formula, as this expression was the most commonly found in literature. The gross rate of photosynthesis was therefore expressed as [6]: 
$P_{\text {net }}=\int_{V} P_{m}(T) \frac{\sigma_{X} I_{\text {loc }}}{K(T)+\sigma_{X} I_{l o c}} X \cdot d V$

103 where $P_{m}$ is the maximum specific rate of photosynthesis $\left(\mathrm{kg} \mathrm{O}_{2} / \mathrm{kg}-\mathrm{s}\right), T$ is the culture

104 temperature $\left({ }^{\circ} \mathrm{C}\right), K$ is the half-saturation constant $(\mathrm{W} / \mathrm{kg}), \sigma_{X}$ is the extinction coefficient

$105\left(\mathrm{~m}^{2} / \mathrm{kg}\right), I_{l o c}$ is the local light intensity $\left(\mathrm{W} / \mathrm{m}^{2}\right.$, as photosynthetically active radiation or PAR),

$106 X$ is the algal concentration $\left(\mathrm{kg} / \mathrm{m}^{3}\right)$ and $V$ is the culture volume $\left(\mathrm{m}^{3}\right)$. The local light intensity

$107 I_{l o c}$ was expressed by using a Beer-Lambert law:

$108 \quad I_{l o c}(l)=I_{0} \exp \left(-\sigma_{X} X l\right)$

109 where $l$ is the light path between the considered location and the reactor external surface $(\mathrm{m})$

110 and $I_{0}$ is the incident light intensity $\left(\mathrm{W} / \mathrm{m}^{2}\right)$. The evolution of $P_{m}$ and $K$ with temperature was

111 fitted to the theoretical model of Bernard and Rémond [11] as this model was shown to

112 satisfyingly fit the evolution of the specific growth rate of 15 algal species. $P_{m}$ and $K$ were

113 therefore expressed as follows:

$114 p=\left\{\alpha \frac{\left(T-T_{\max }\right)\left(T-T_{\min }\right)^{2}}{\left(T_{o p t}-T_{\min }\right)\left(\left(T_{o p t}-T_{\min }\right)\left(T-T_{o p t}\right)-\left(T_{o p t}-T_{\max }\right)\left(T_{o p t}+T_{\min }-2 T\right)\right)}\right.$ if $T_{\min } \leq T \leq T_{\max }$ 0 otherwise

115 where $p$ represents either $P_{m}$ or $K, \alpha$ is the maximum value of $P_{m}$ or $K$, and $T_{\min }, T_{\max }$ and $T_{\text {opt }}$

116 are the minimum, maximum, and optimum temperatures for photosynthesis $\left({ }^{\circ} \mathrm{C}\right)$, respectively.

117 The rate of endogenous respiration was expressed using a first-order law:

$118 \quad E R=\lambda(T) X V$

119 where $\lambda$ is the specific respiration rate $\left(\mathrm{kg} \mathrm{O}_{2} / \mathrm{kg}-\mathrm{s}\right)$. Several studies showed that the rate of

120 respiration was an exponential function of temperature [12-14]. The parameter $\lambda$ was

121 therefore expressed as follows:

$122 \lambda(T)=\lambda_{0} \exp (\beta T)$

123 where $\lambda_{0}\left(\mathrm{~kg} \mathrm{O}_{2} / \mathrm{kg}^{-\mathrm{s}^{-1}}\right)$ and $\beta\left({ }^{\circ} \mathrm{C}^{-1}\right)$ are determined experimentally. 
126 The device used for calibration was composed of six cylindrical glass reactors (diameter: 3.48 $\mathrm{cm}$; height: $5.82 \mathrm{~cm}$; volume: $55.2 \mathrm{~mL}$ ) all equipped with an oxygen electrode (Model DO50GS, Hach) measuring both dissolved oxygen and medium temperature. Each reactor was positioned over a LED lamp (12V PHILIPS EnduraLED 10W MR16 Dimmable 4000 K) which light intensity was independently controlled. A typical experiment consisted on measuring first oxygen production rates when algae were exposed to light (light-phase) and then respiration rates when algae were in the dark (dark phase). These measurements were performed for six different light intensities (range: $0-460 \mathrm{~W} / \mathrm{m}^{2}$, as PAR) and under constant

134 temperature (see [6] for a complete description of the oxygen measurements). These 135 experiments were then repeated for 6 different temperatures $\left(3.73^{\circ} \mathrm{C} ; 10.2^{\circ} \mathrm{C} ; 19.7^{\circ} \mathrm{C}, 27.7^{\circ} \mathrm{C}\right.$, $13634.7^{\circ} \mathrm{C} ; 40.9^{\circ} \mathrm{C}$ ). Temperature was maintained constant (within approximately $+/-1^{\circ} \mathrm{C}$ ) during 137 the entire duration of the experiment by circulating temperature-controlled air around the 138 reactors. The light intensity reaching the external surface of each reactor was measured by 139 actinometry (see $\mathrm{S} 1$ for details). The parameters $P_{m}$ and $K$ for each temperature were 140 determined by least-square fitting using the lsqcurvefit Matlab function. Respiration rates 141 during the dark periods were found to be independent on the light intensity cells where exposed to during the light phase and the parameter $\lambda$ was determined from the average respiration rate in the six reactors. The parameters $T_{\min }, T_{\max }, T_{o p t}$, were obtained by least-

144 square fitting (using the lsqcurvefit Matlab function) and the parameters $\lambda_{0}$ and $\beta$ were 145 estimated by log-linear regression. Algae were found to be photosynthetically inactive after 146 exposure to $43^{\circ} \mathrm{C}$ for $30 \mathrm{~min}$ (unpublished data). $P_{m}$ was therefore considered null at $43^{\circ} \mathrm{C}$ 147 when determining $T_{\min }, T_{\max }$, and $T_{\text {opt }}$. Based on the linear relationship between $P_{m}$ and $K$ (see 148 section 3.1 for details), $K$ was also assumed null at this temperature. 
151 The extinction coefficient $\sigma_{X}$ was experimentally determined by measuring the light 152 intensities entering and exiting the reactors for different algal concentrations (see S2 for 153 details). Similarly to the formula proposed by [15], the extinction coefficient was expressed as 154 follows:

$\sigma_{X}=A X^{B}$

156 where $A$ and $B$ are empirical coefficients $(A=79.1 ; B=-0.37$, see $\mathrm{S} 2$ for details $)$. The dependence of the extinction coefficient on algal concentration was mostly due to light scattering by algal cells. Scattered photons indeed exited the reactors through the lateral side of the reactors. This effect was reinforced by the fact that LEDs lamps did not emit light in a vertical direction but in a cone of an angle $30^{\circ}$, which increases the fraction of light lost through the reactors lateral sides. When the algal concentration increased, most of photons were absorbed by algal cells and the fraction of light exiting the reactors through the lateral

163 sides decreased. This explains why the extinction coefficient is less sensitive to $X$ for high 164 algal concentrations (Equation 7; see S2 for further detail). Calibration experiments were 165 therefore performed at relatively high algal concentrations to ensure that most of incoming 166 light was absorbed by algae.

\subsection{Application to the calibration device}

169 Based on Equations 1-7, the algal productivity in each reactor used for model calibration was expressed as follows:

$P_{n e t}\left(T, I_{0}\right)=\frac{P_{m}(T) S}{\sigma_{X}} \ln \left(\frac{K(T)+\sigma_{X} I_{0}}{K(T)+\sigma_{X} I_{0} \cdot \exp \left(-\sigma_{X} X L\right)}\right)-\lambda(T) X S L$

172 where $T$ is the culture temperature $\left({ }^{\circ} \mathrm{C}\right), I_{0}$ is the incident light intensity at the reactor bottom

$173\left(\mathrm{~W} \mathrm{~m}^{-2}\right), P_{m}, K$ and $\lambda$ are the temperature-dependent model parameters (see Equations 4 and 
$1746), \sigma_{X}$ is the extinction coefficient (see Equation 7), $X$ is the algal concentration $\left(\mathrm{kg} \mathrm{m}^{-3}\right)$, and

$175 L$ and $S$ are the reactor height $(\mathrm{m})$ and section surface area $\left(\mathrm{m}^{2}\right)$, respectively.

177 2.6. Monte-Carlo simulations

178 Monte-Carlo simulations were performed to quantify the impact of experimental error on the

179 fitted values of model parameters $P_{m}, K$ and $\lambda$. Namely, four key measurements were found to 180 have a significant impact on model parameters:

$181 \quad$ - The extinction coefficient $\sigma_{X}$ : coefficients $A$ and $B$ in Equation 7 were found to vary in the ranges $74.50-82.78$ and $-0.20--0.48$, respectively (see S2 for details);

- The dissolved oxygen concentration: oxygen probes were found to be accurate at $+/$ -

$$
4.7 \% \text { (see S3 for details); }
$$

- The incident light intensity $I_{0}$ : Measurements by actinometry were assumed to be accurate at $+/-10 \%$ based on the study of Hatchard and Parker [16] (See S1 for details).

- The algal concentration $X$ : an accuracy of $+/-7 \%$ on dry weight measurements was assumed by analogy with the study of Béchet et al. [6].

In practice, the uncertainties on the parameters $P_{m}, K$ and $\lambda$ were obtained from the following Monte-Carlo approach. Assuming that errors were normally distributed, a large artificial data set was generated by adding a normally distributed error to the measurements (algal concentration $X$, light intensity $I_{0}$ and oxygen concentration) and the extinction coefficient $\left(\sigma_{X}\right)$. A total of 2000 artificial data sets were thus generated and the parameters $P_{m}, K$ and $\lambda$ were determined with a minimization algorithm for each data set. This approach yielded a normal distribution for $P_{m}, K$ and $\lambda$, which allowed determining confidence intervals for each of these parameters. These resulting confidence intervals were then used to determine levels 
of uncertainty on the parameters $T_{\min }, T_{\max }, T_{o p t}, \lambda_{0}$ and $\beta$ through another set of Monte-Carlo

200 simulations (see [6] for further details on Monte-Carlo simulations).

2.7. Conversion coefficients from oxygen to biomass productivity

203

The productivity model developed in this study predicts algal productivity in terms of oxygen

204 (see Equations 1-6). For engineering purposes, it is however necessary to express

205 productivities in terms of biomass. The conversion from oxygen to biomass productivities

206 was performed by following the approach of Béchet et al. [6]. This conversion was based on

207 the assumption of a photosynthetic quotient of 1 mole of $\mathrm{CO}_{2}$ consumed for the production of

2081 mole of $\mathrm{O}_{2}$ during the light reactions of photosynthesis, which was supported by the

209 experimental measurement of the photosynthetic quotient of a close algal species (Dunaliella

210 tertiolecta) by Wegmann and Metzner [17]. This photosynthetic quotient of 1 does not

211 include respiratory mechanisms and only reflects photosynthesis. From the knowledge of

212 algal composition and by considering that nitrate was used as a nitrogen source, the following

213 conversion coefficients were obtained (see S4 for details):

$214 \quad-\quad P_{m}{ }^{\prime}[\mathrm{kg} / \mathrm{kg}-\mathrm{s}]=0.75( \pm 0.10) P_{m}[\mathrm{~kg} \mathrm{O} / \mathrm{kg}-\mathrm{s}]$

$215-\lambda^{\prime}[\mathrm{kg} / \mathrm{kg}-\mathrm{s}]=0.75( \pm 0.10) \lambda[\mathrm{kg} \mathrm{O} / \mathrm{kg}-\mathrm{s}]$ at daytime

$216-\lambda^{\prime}[\mathrm{kg} / \mathrm{kg}-\mathrm{s}]=0.9375( \pm 0.10) \lambda[\mathrm{kg} \mathrm{O} / \mathrm{kg}-\mathrm{s}]$ at nighttime

218 3. Results and discussion

219 3.1. Rate of photosynthesis

220 Figure 1 shows that the Type-II model coupling a Monod formula with the modified Beer-

221 Lambert law was able to describe the evolution of the rate of photosynthesis with light

222 intensity. These PI-curves do not exhibit the typical decrease at high light intensities due to 
223 photo-inhibition observed for $D$. salina in dilute cultures through chlorophyll fluorescence

224 measurements by Combe et al. [18]. This is explained by the high algal concentration that

225 ensured that only a small fraction of cells were photo-inhibited, so that the impact of photo-

226 inhibition was minimal, as suggested by Bernard [19]. Experimental errors caused relatively

227 high uncertainty on fitted values of $P_{m}$ and $K$ as shown in Table 1 and especially at the

228 temperature of $40.9^{\circ} \mathrm{C}$ as the gross productivity was only measured at two light intensities (the

229 oxygen net productivity was negative at low light intensities due to high respiration rates at

230 this temperature, and oxygen concentration remained null during all experiment). Because of

231 these experimental uncertainties, it was difficult to accurately identify $P_{m}$ and $K$ separately. In

232 other words, various combinations of $P_{m}$ and $K$ could yield equally satisfying fits in Figure 1.

233 In spite of these levels of inaccuracy, Figure 2 shows that $P_{m}$ and $K$ were correlated $\left(\mathrm{R}^{2}=\right.$

234 0.87558), which was previously observed by Béchet et al. [6]. The ratio $P_{m} / K$ indeed

235 represents the maximum 'yield' of photosynthesis (in $\mathrm{kg} \mathrm{O}_{2} / \mathrm{W}$-s), i.e. the amount of oxygen

236 produced through photosynthesis per unit light energy captured by cells. For low light

237 intensities, this maximum yield is theoretically independent of temperature [20], which

238 explains the linearity observed in Figure 2.

240 Figure 3 shows that experimental values of $P_{m}$ followed a typical response to temperature

241 characterized by a slow increase from cold to optimal temperatures before a fast drop for

242 higher temperatures. The model of Bernard and Rémond [11] especially developed for this

243 type of temperature response thus provides a good fit to experimental data (Figure 3).

244 Interestingly, the model of Bernard and Rémond successfully described the evolution of $K$, 245 with similar values for $T_{\min }, T_{\max }$, and $T_{o p t}$ as shown in Table 2 . This similarity is explained by

246 the linearity between $P_{m}$ and $K$ shown in Figure 2. The values of $T_{\min }, T_{o p t}$ and $T_{\max }$ are within

247 the range of values obtained by Bernard and Rémond [11] for 15 other algal species. The 
value of the maximum temperature $T_{\max }$ is in the upper range of reported values for other algal

249 species, which may be explained by two reasons. Firstly, D. salina is known to resist to high

250 temperatures as this species is naturally found in shallow water bodies in which temperature

251 can reach relatively high values [21,22]. In addition, this model calibration is based on short-

252 term measurements of photosynthesis (approximately 30 min) while Bernard and Rémond

253 [11] fitted their model on growth rate measurements obtained over several days of cultivation.

254 Even if Bernard and Rémond [11] did not calibrate their model on D. salina data, this

255 difference in time scales may explain the relatively high $T_{\max }$ value $\left(43^{\circ} \mathrm{C}\right)$ as short-term and

256 long-term algal responses are not controlled by the same biological processes. Oxygen

257 production indeed reflects the rate of initial non-enzymatic steps of photosynthesis (usually

258 referred to as "light reactions"), while carbon fixation through Calvin cycle and more

259 generally growth involve enzymatic processes that are more impacted by temperatures. For

260 example, Béchet et al. [6] showed that Chlorella vulgaris was unable to sustain growth at a

261 constant temperature of $35^{\circ} \mathrm{C}$ for more than 1-2 hours while the oxygen productivity peaked at

$26238^{\circ} \mathrm{C}$. The uncertainty on $P_{m}$ and $K$ showed in Table 1 caused levels of uncertainty on $T_{\max }$,

$263 T_{\min }$ and $T_{\text {opt }}$ similar to the confidence intervals presented by Bernard and Rémond [11], even

264 if methods for uncertainty estimations were based on different approaches (Table 2).

\subsection{Respiration rate}

267 Figure 4 shows that the specific respiration rate increased exponentially with temperature over

268 the range of temperatures tested. Similar observations were reported for a large number of

269 algal species as reviewed by Robarts and Zohary [23]. Based on the values reported in Table

2701 , the coefficients $\lambda_{0}$ and $\beta$ (with corresponding confidence intervals at 95\%) were $6.4510^{-7}$

$271\left(+/-0.3410^{-7}\right) \mathrm{s}^{-1}$ and $0.0715(+/-0.0002){ }^{\circ} \mathrm{C}^{-1}$, respectively. 
274 The results obtained during the model calibration performed on $D$. salina are consistent with

275 prior observations in the literature, namely:

276 - The rate of gross oxygen productivity followed a typical Monod-like response to light $277 \quad$ intensity;

278 - The maximum specific rate of oxygen production was linearly correlated to the half-

279 saturation constant of the Monod model, indicating that oxygen production efficiency

280 is as expected independent of temperature at low light intensities;

281 - The evolutions of the maximum specific rate of photosynthesis and half-saturation

282 constant with temperature satisfyingly fitted Bernard and Rémond's model.

283 - Respiration rates were shown to increase exponentially with temperature, which is

$284 \quad$ consistent with prior observations in the literature.

$285 \quad$ - These results also confirm that Dunaliella salina can grow in a relatively wide

286 temperature range and resist to relatively high temperatures.

287 These results indicate that the experimental technique used for model calibration is valid 288 and that the productivity model should yield accurate predictions in outdoor cultivation 289 systems.

293 Acknowledgments:

294 The authors are grateful for the support of the ANR-13-BIME-004 Purple Sun and the 295 Inria Project Lab Algae in silico. Margaux Caïa (Inria BIOCORE/LOV) is acknowledged 296 for early work on the device used for model calibration. 
299 [1] Q. Béchet, A. Shilton, B. Guieysse, Modeling the effects of light and temperature on algae growth: State of the art and critical assessment for productivity prediction during outdoor cultivation, Biotechnol. Adv. 31 (2013) 1648-1663.

[2] E. Lee, M. Jalalizadeh, Q. Zhang, Growth kinetic models for microalgae cultivation: A review, Algal Res. 12 (2015) 497-512. doi:10.1016/j.algal.2015.10.004.

[3] O. Bernard, F. Mairet, B. Chachuat, Modelling of Microalgae Culture Systems with 305 Applications to Control and Optimization, in: C. Posten, S. Feng Chen (Eds.), Microalgae Biotechnol., Springer International Publishing, Cham, 2016: pp. 59-87. doi:10.1007/10_2014_287.

[4] P.M. Slegers, P.J.M. van Beveren, R.H. Wijffels, G. Van Straten, A.J.B. van Boxtel, Scenario analysis of large scale algae production in tubular photobioreactors, Appl. Energy. 105 (2013) 395-406. doi:10.1016/j.apenergy.2012.12.068.

Q. Béchet, A. Shilton, B. Guieysse, Maximizing Productivity and Reducing Environmental Impacts of Full-Scale Algal Production through Optimization of Open Pond Depth and Hydraulic Retention Time, Environ. Sci. Technol. (2016) acs.est.5b05412. doi:10.1021/acs.est.5b05412.

Q. Béchet, P. Chambonnière, A. Shilton, G. Guizard, B. Guieysse, Algal productivity modeling: A step toward accurate assessments of full-scale algal cultivation, Biotechnol. Bioeng. 112 (2015) 987-996. doi:10.1002/bit.25517.

318 [7] J. Benemann, Microalgae for biofuels and animal feeds, Energies. 6 (2013) 5869-5886. doi:10.3390/en6115869.

Q. Béchet, A. Shilton, B. Guieysse, Full-scale validation of a model of algal productivity, Environ. Sci. Technol. 48 (2014) 13826-13833. 
Hustedt and Denotula Confervacea (CLEVE) Gran., Can. J. Microbiol. 8 (1962) 229_

324

325

326

327 239. doi:10.1139/m62-029.

[10] C.J. Zhu, Y.K. Lee, Determination of biomass dry weight of marine microalgae, J. Appl. Phycol. 9 (1997) 189-194. doi:10.1023/A:1007914806640.

[11] O. Bernard, B. Rémond, Bioresource Technology Validation of a simple model accounting for light and temperature effect on microalgal growth, Bioresour. Technol. 123 (2012) 520-527. doi:10.1016/j.biortech.2012.07.022.

[12] C.D. Collins, C.W. Boylen, Physiological responses of Anabaena variabilis (Cyanophyceae) to intantaneous exposure to various combinations of light intensity and temperature, J. Phycol. 18 (1982) 206-211.

[13] J.U. Grobbelaar, C.J. Soeder, Respiration losses in planktonic green algae cultivated in raceway ponds, J. Plankton Res. 7 (1985) 497-506. doi:10.1093/plankt/7.4.497.

[14] F. Le Borgne, J. Pruvost, Investigation and modeling of biomass decay rate in the dark and its potential influence on net productivity of solar photobioreactors for microalga Chlamydomonas reinhardtii and cyanobacterium Arthrospira platensis, Bioresour. Technol. 138 (2013) 271-276. doi:10.1016/j.biortech.2013.03.056.

[15] A. Morel, Optical modeling of the upper ocean in relation to its beiogenous matter content (case I waters), J. Geophys. Res. 93 (1988) 10749-10768. doi:10.1029/JC093iC09p10749.

[16] C.G. Hatchard, C.A. Parker, A New Sensitive Chemical Actinometer. II. Potassium Ferrioxalate as a Standard Chemical Actinometer, Proc. R. Soc. London A Math. Phys. Eng. Sci. 235 (1956) 518-536. http://rspa.royalsocietypublishing.org/content/235/1203/518.abstract.

[17] K. Wegmann, H. Metzner, Synchronization of Dunaliella cultures, Arch. Mikrobiol. 78 (1971) 360-367. doi:10.1007/BF00412276. 
348 [18] C. Combe, P. Hartmann, S. Rabouille, A. Talec, O. Bernard, A. Sciandra, Long-term adaptive response to high-frequency light signals in the unicellular photosynthetic eukaryote Dunaliella salina, Biotechnol. Bioeng. 112 (2015) 1111-1121.

[19] O. Bernard, Hurdles and challenges for modelling and control of microalgae for CO 2 mitigation and biofuel production, J. Process Control. 21 (2011) 1378-1389. doi:10.1016/j.jprocont.2011.07.012.

[20] I.R. Davison, Environmental effects on algal photosynthesis: temperature, J. Phycol. 27 (1991) 2-8. doi:10.1111/j.0022-3646.1991.00002.x.

[21] L.J. Borowitzka, M.A.. Borowitzka, Commercial Production of $\beta$-carotene by Dunaliella salina in open ponds, Bull. Mar. Sci. 47 (1990) 244-252.

358 [22] P.I. Gómez, M.A. González, The effect of temparature and irradiance on the growth and carotenogenic capacity of seven strains of Dunaliella salina (Chlorophyta) cultivated under laboratory conditions, Biol. Res. 38 (2005) 151-162.

361 [23] R.D. Robarts, T. Zohary, Temperature effects on photosynthetic capacity, respiration, and growth rates of bloom-forming cyanobacteria, New Zeal. J. Mar. Freshw. Res. 21 (1987) 391-399. doi:10.1080/00288330.1987.9516235. 
365 Table 1: Model parameters values at different temperatures (values in parenthesis indicate

366 confidence level at 95\% estimated through Monte-Carlo simulations). Values of $P_{m}$ and $\lambda$ in

$367 \mathrm{~kg} / \mathrm{kg}$-s can be obtained by using the conversion coefficients provided in Section 2.6. Values

368 of $K$ can be obtained in $\mu \mathrm{mol} / \mathrm{kg}$-s by using a conversion factor of $4.79 \mu \mathrm{mol} / \mathrm{W}$-s (based on

369 the spectral distribution of device lamps shown in S1).

\begin{tabular}{|l|c|c|c|c|c|c|}
\hline Temperature $\left({ }^{\circ} \mathrm{C}\right)$ & 3.7 & 10.2 & 19.7 & 27.7 & 34.7 & 40.9 \\
\hline$P_{m}\left(10^{-4} \mathrm{~kg} \mathrm{O} / \mathrm{kg}-\mathrm{s}\right)$ & 0.165 & 0.571 & 1.19 & 2.08 & 1.77 & 1.35 \\
& $(0.014)$ & $(0.096)$ & $(0.25)$ & $(0.43)$ & $(0.33)$ & $(0.88)$ \\
\hline$K\left(10^{4} \mathrm{~W} / \mathrm{kg}\right)$ & 0.479 & 2.46 & 2.79 & 4.77 & 3.34 & 3.28 \\
& $(0.095)$ & $(0.64)$ & $(0.87)$ & $(1.34)$ & $(0.89)$ & $(3.31)$ \\
$\lambda\left(10^{-6} \mathrm{~kg} \mathrm{O} / \mathrm{kg}-\mathrm{s}\right)$ & 0.88 & 1.22 & 2.55 & 5.45 & 7.53 & 11.5 \\
& $(0.05)$ & $(0.06)$ & $(0.13)$ & $(0.28)$ & $(0.39)$ & $(0.6)$ \\
\hline
\end{tabular}


371 Table 2: Bernard and Rémond's model parameters for $P_{m}$ and $K$ (values in parenthesis indicate

372 confidence interval at 95\% estimated through Monte-Carlo simulations) - Symbols are

373 defined in Equation 4. Values of $\alpha$ for $K$ can be obtained in $\mu \mathrm{mol} / \mathrm{kg}$-s by using a conversion

374 factor of $4.79 \mu \mathrm{mol} / \mathrm{W}-\mathrm{s}$

\begin{tabular}{|l|l|l|l|l|}
\hline Parameter (unit) & $T_{\min }\left({ }^{\circ} \mathrm{C}\right)$ & $T_{\text {opt }}\left({ }^{\circ} \mathrm{C}\right)$ & $T_{\max }\left({ }^{\circ} \mathrm{C}\right)$ & $\alpha$ \\
\hline$P_{m}(\mathrm{~kg} \mathrm{O} / \mathrm{kg}-\mathrm{s})$ & $-7.8(8.4)$ & $34.0(3.9)$ & $43.0(0.1)$ & $2.0810^{-4} \mathrm{~kg}$ \\
& & & & $\mathrm{O}_{2} / \mathrm{kg}-\mathrm{s}$ \\
\hline$K(\mathrm{~W} / \mathrm{kg})$ & $-15.4(17.3)$ & $33.7(8.0)$ & $43.0(0.4)$ & $4.7710^{4} \mathrm{~W} / \mathrm{kg}$ \\
\hline
\end{tabular}


Figures

378 Figure 1: Gross rate of photosynthesis vs. incident light intensity at different temperatures

379 (dots: experimental data; plain lines: theoretical fitting) - Error bars represent standard

380 deviation of error caused by experimental error. Light intensities in $\mathrm{W} / \mathrm{m}^{2}$ can be converted

381 into $\mu \mathrm{mol} / \mathrm{m}^{2}$-s by using a conversion factor of $4.79 \mu \mathrm{mol} / \mathrm{W}$-s.

382

383 Figure 2: Values of the maximum specific growth rate $P_{m}$ vs. the half-constant $K$ (dots:

384 experimental data; plain line: linear regression) - Error bars indicate the standard deviation

385 estimated through Monte-Carlo simulations.

386

387 Figure 3: Evolution of the maximum specific oxygen productivity and half-saturation constant

388 with temperature (dots: experimental data; plain line: fitting with Bernard and Rémond's

389 model) - Error bars represent the standard deviation estimated through Monte-Carlo

390 simulations. Values of $K$ can be obtained in $\mu \mathrm{mol} / \mathrm{kg}$-s by using a conversion factor of 4.79

$391 \mu \mathrm{mol} / \mathrm{W}-\mathrm{s}$.

392

393 Figure 4: Evolution of the respiration specific rate with temperature (dots: experimental data;

394 plain line: fitting to an exponential function as described by Equation 6) - Error bars represent

395 standard deviation estimated through Monte-Carlo simulations. 
Figure 1

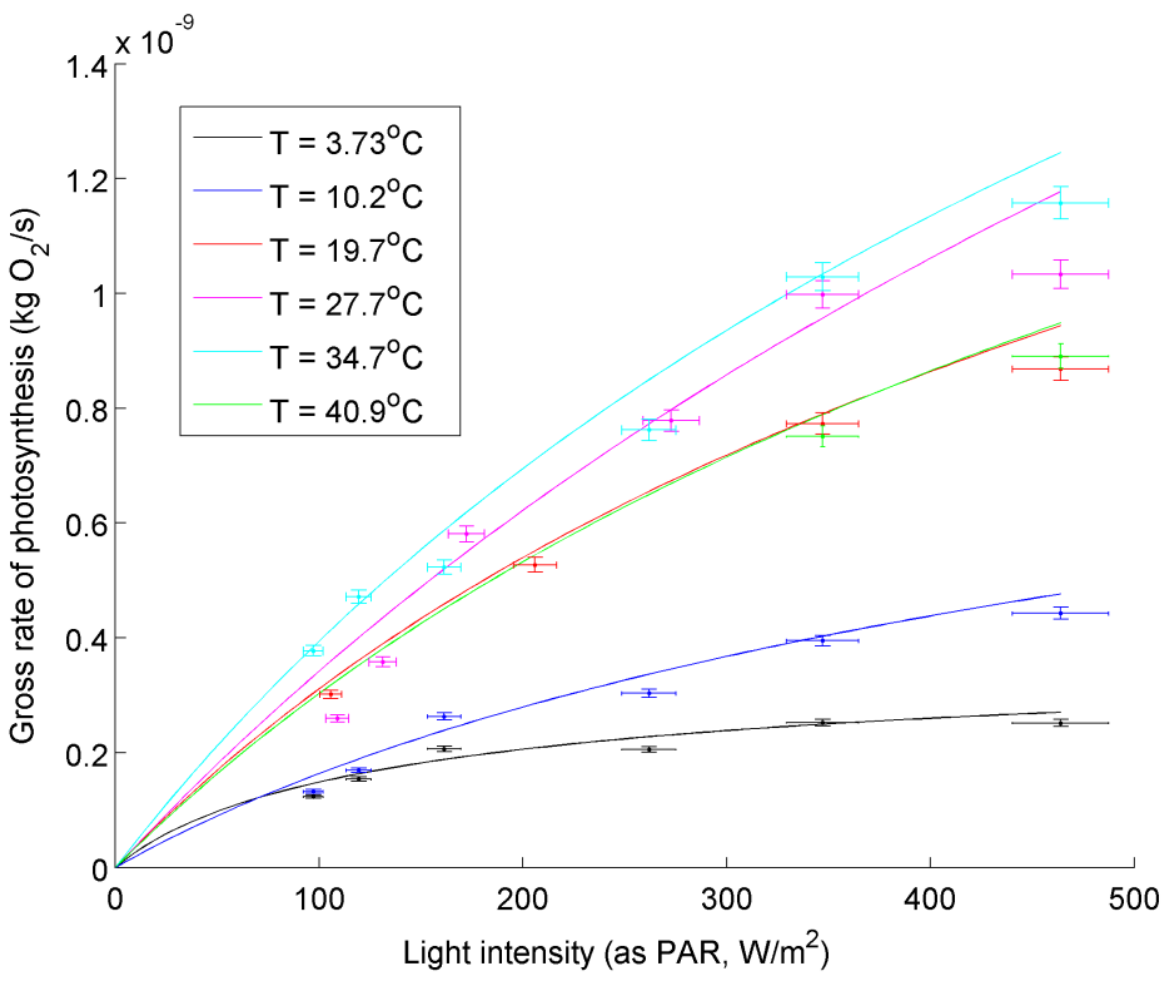


Figure 2

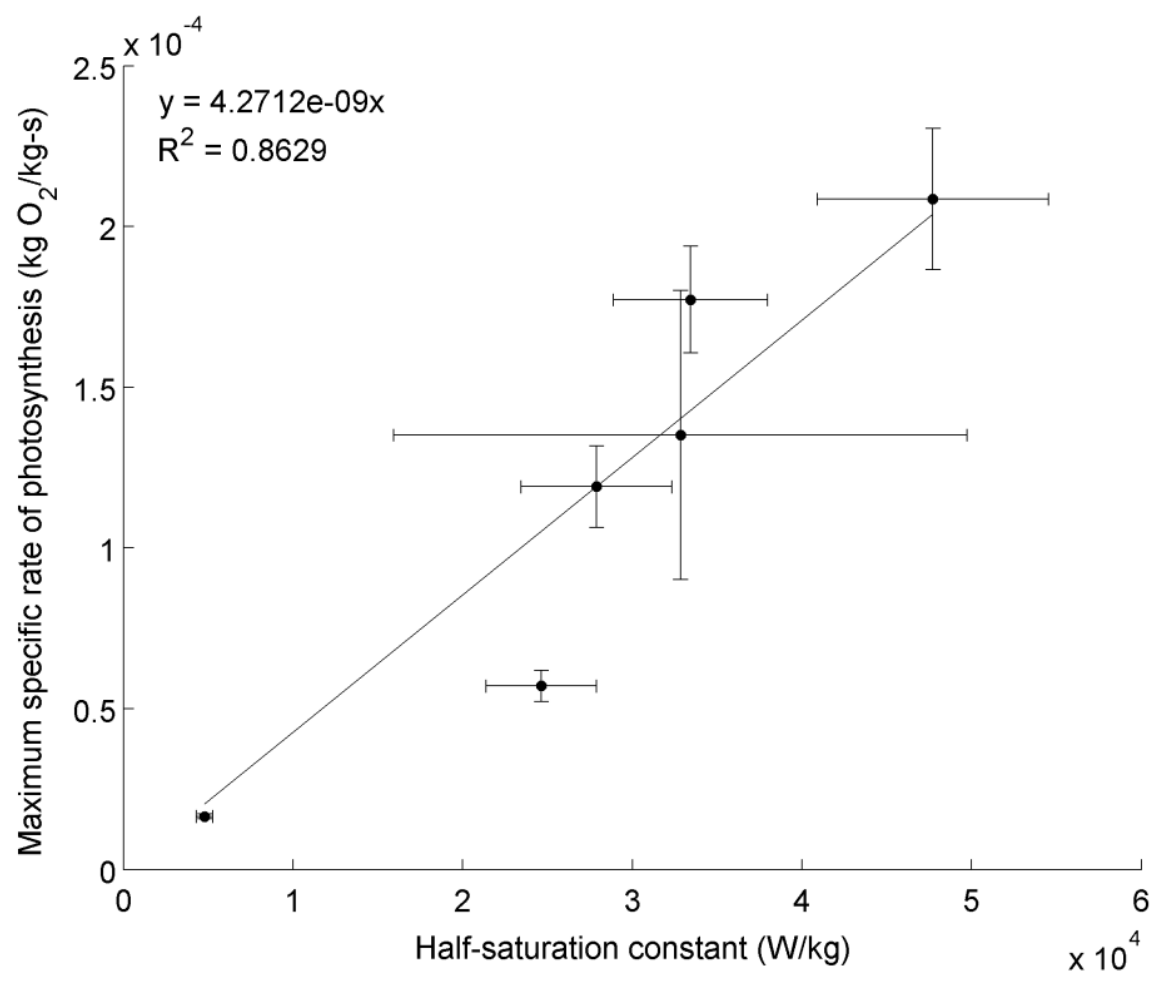

399 
Figure 3
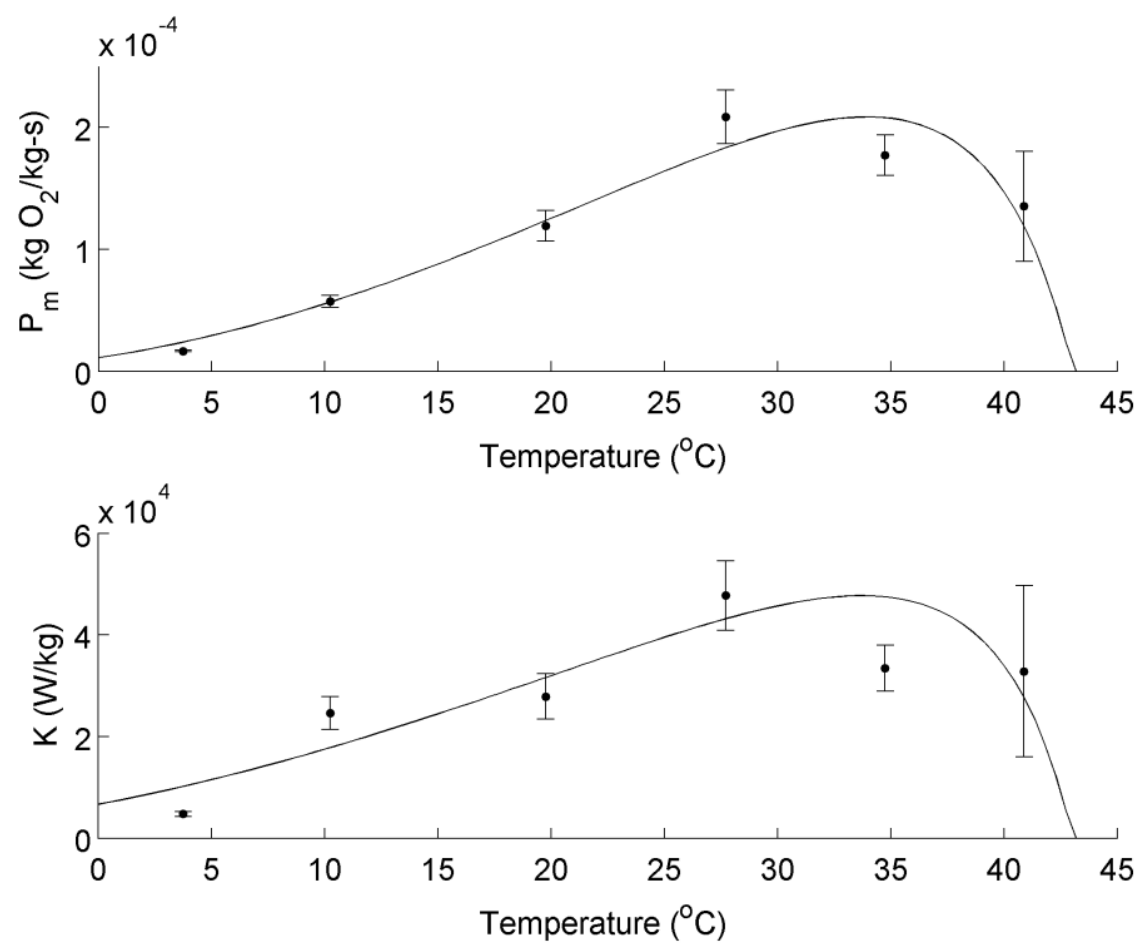

401 
402 Figure 4

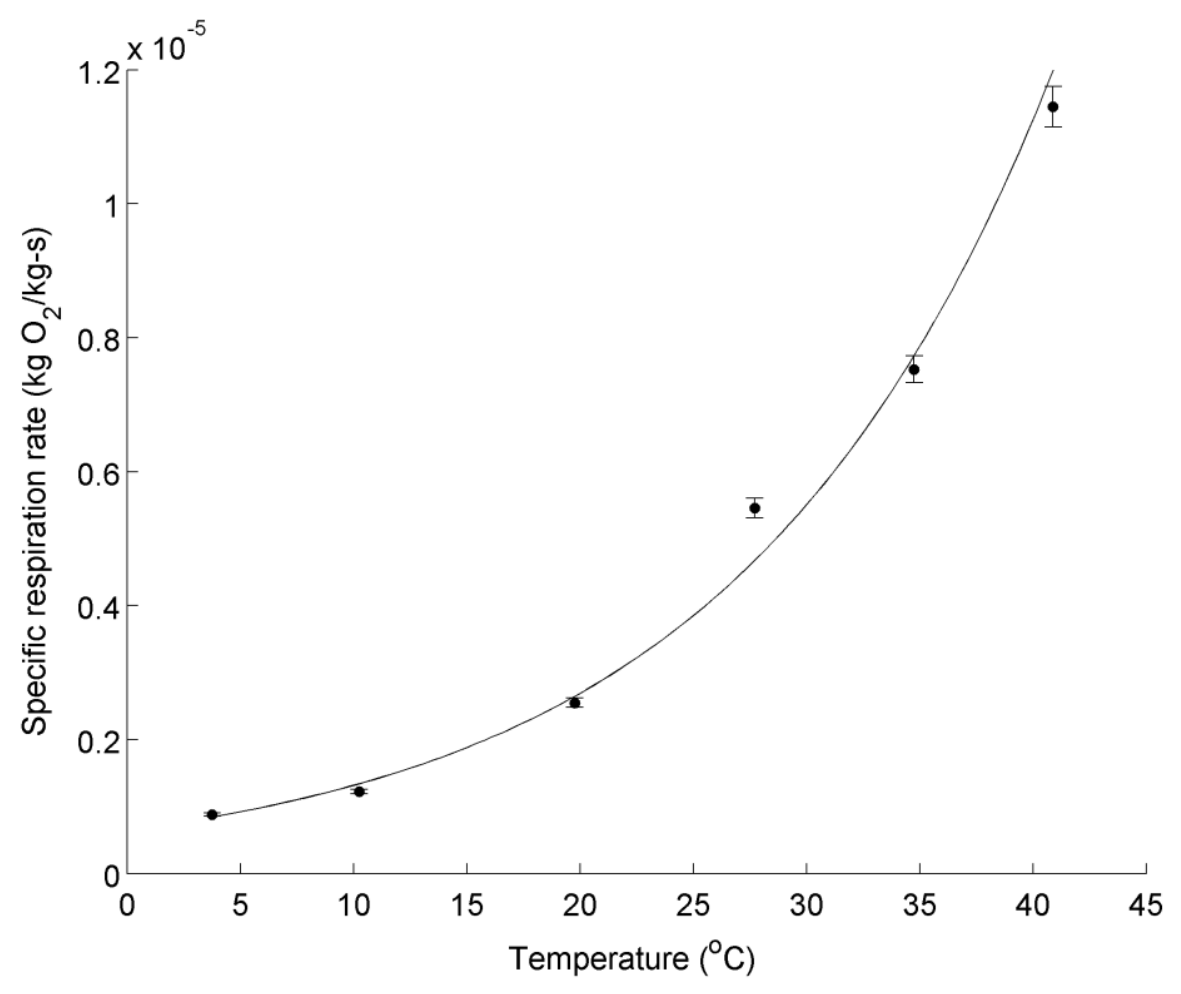

403 